\title{
Pelabelan Lokal Titik Graf Hasil Diagram Lattice Subgrup $\mathbb{Z}_{n}$
}

\author{
Ikhsanul Halikin \\ Program Studi Matematika, Fakultas MIPA, Universitas Jember \\ Jl. Kalimantan No.37 Kampus Tegalboto, Jember, 68121, Indonesia \\ E-mail: ikhsan.fmipa@unej.ac.id
}

Article History:

Received: $x x-x x-x x x x$; Received in revised form: $x x-x x-x x x x$; Accepted: $x x-x x-x x x x$;

Available online: $\mathrm{xx}-\mathrm{xx}-\mathrm{xxxx}$

\begin{abstract}
A group is a system that contains a set and a binary operation satisfying four axioms, i.e., the set is closed under binary operation, associative, has an identity element, and each element has an inverse. Since the group is essentially a set and the set itself has subsets, so if the binary operation is applied to its subsets then it satisfies the group's four axioms, the subsets with the binary operation are called subgroups. The group and subgroups further form a partial ordering relation. Partial ordering relation is a relation that has reflexive, antisymmetric, and transitive properties. Since the connection of subgroups of a group is partial ordering relation, it can be drawn a lattice diagram. The set of integers modulo $n, \mathbb{Z}_{n}$, is a group under addition modulo $n$. If the subgroups of $\mathbb{Z}_{n}$ are represented as vertex and relations that is connecting two subgroups are represented as edgean, then a graph is obtained. Furthermore, the vertex in this graph can be labeled by their subgroup elements. In this research, we get the result about the characteristic of the lattice diagram of $\mathbb{Z}_{n}$ and the existence of vertex local labeling.
\end{abstract}

Keywords: Lattice Diagram; Subgroup; Vertex Local Labelling.

\section{Abstrak}

Grup merupakan sistem yang memuat sebuah himpunan dan operasi biner yang memenuhi 4 aksioma, yaitu operasi pada himpunannya bersifat tertutup, assosiatif, memiliki elemen identitas, dan setiap elemennya memiliki invers. Grup pada dasarnya adalah himpunan dan himpunan itu memiliki himpunan bagian. Jika operasi tersebut diberlakukan pada himpunan bagiannya dan memenuhi 4 aksioma grup maka himpunan bagian dan operasi tersebut disebut subgrup. Grup dan subgrup ini selanjutnya membentuk suatu relasi pengurutan parsial. Relasi pengurutan parsial adalah suatu relasi yang memiliki sifat refleksif, antisimetris, dan transitif. Oleh karenanya, relasi subgrup-subgrup dari suatu grup ini dapat digambar diagram latticenya. Himpunan bilangan bulat modulo $n, \mathbb{Z}_{n}$, merupakan grup terhadap operasi penjumlahan modulo n. Jika subgrup pada $\mathbb{Z}_{n}$ direpresentasikan sebagai titik dan relasi yang menghubungkan dua buah subgrupnya direpresentasikan sebagai sisi, maka diperoleh suatu graf. Titik-titik pada graf ini dapat dilabeli berdasarkan elemenelemen subgrupnya. Pada penelitian ini diperoleh hasil kajian mengenai karakteristik diagram lattice subgrup $\mathbb{Z}_{n}$ dan eksistensi pelabelan lokal titiknya.

Kata Kunci: Diagram Lattice, Subgrup, Pelabelan Lokal Titik. 


\section{Pendahuluan}

Suatu struktur aljabar merupakan suatu sistem yang memuat dua unsur utama yakni sebuah himpunan dan operasi biner yang didefinisikan didalamnya. Operasi biner pada suatu himpunan, misalkan himpunan $G$, adalah sebuah aturan yang memasangkan setiap pasangan terurut elemenelemen himpunan $G$, misalkan $(a, b)$, dengan satu elemen dalam $G$. Suatu himpunan tak kosong $G$ dan sebuah operasi biner * (selanjutnya dinotasikan dengan $(G, *))$ disebut grup jika dan hanya jika memenuhi 4 aksioma sebagai berikut: 1

1. $\forall(a, b \in G),(\exists c \in G), \exists a * b=c$

2. $\forall(a, b, c \in G),(a * b) * c=a *(b * c)$

3. $(\exists e \in G), \ni(\forall a \in G), a * e=e * a=a$

4. $(\forall a \in G),\left(\exists a^{-1} \in G\right), \ni a * a^{-1}=a^{-1} * a=e$

Jika grup $(G, *))$ memenuhi sifat $a * b=b * a$ untuk setiap $a, b \in G$ maka grup $(G, *)$ disebut grup abelian. Selanjutnya, jika operasi biner $*$ juga diterapkan untuk himpunan bagian dari $G$, misalkan $H \subseteq G$, maka $H$ dan operasi biner * yang juga memenuhi 4 aksioma grup di atas dinamakan subgrup dari $G$ dan disimbolkan dengan $H \leq G$. Sebagai contoh, misalkan $\mathbb{Z}_{n}=\{0,1, \ldots, n-1\}$, maka untuk $n \geq 1,\left(\mathbb{Z}_{n},+_{n}\right)$ adalah sebuah grup abelian dengan $+_{n}$ notasi operasi penjumlahan modulo n. Elemen identitasnya adalah 0 dan untuk $m \in \mathbb{Z}_{n}$ dengan $m \neq 0$, invers dari $m$ adalah $n-m$. Grup $\left(\mathbb{Z}_{n},+_{n}\right)$ sering dinamakan dengan grup bilangan bulat modulo $n \cdot\left(k \mathbb{Z}_{n},+_{n}\right)$ dengan $k \in \mathbb{Z}_{n}$ adalah salah satu subgrupnya ${ }^{2}$.

Ordo(atau Orde) dari suatu grup $G$ adalah banyaknya elemen dari $G$ dan dinotasikan dengan $|G|$. Jika banyaknya elemen $G$ tak berhingga, maka ordo dari $\mathrm{G}$ adalah tak berhingga. Misalkan $a$ adalah suatu elemen dari grup $G$, ordo dari $a$ adalah $n$ jika dan hanya jika $n$ merupakan bilangan bulat positif terkecil sedemikian hingga $a^{n}=e$, dimana $e$ merupakan elemen identitas pada grup $G$. Sedangkan jika tidak ada bilangan bulat positif yang demikian maka dikatakan bahwa ordo dari $a$ tak hingga. Ordo dari $a$ dinotasikan $\vartheta(a)$.

${ }^{1}$ I. N. Herstein, Abstract Algebra 3th (Third) Edition (Example Product Manufacturer, 1996), 41.

${ }^{2}$ Charles Roberts, Introduction to Mathematical Proofs: A Transition, 1 edition (Boca Raton: Chapman and Hall/CRC, 2009), 300. 


\section{Pelabelan Lokal Titik Graf...}

Grup $G$ disebut sebagai grup siklik jika ada $a \in G$ sedemikian hingga setiap $x \in G$ dapat dinyatakan sebagai $x=a^{m}$, dengan $m$ merupakan bilangan bulat. Elemen $a$ disebut elemen pembangun atau generator dan $G$ disebut grup siklik yang dibangun oleh $a$ dan dinotasikan dengan $\langle a\rangle=G$. Grup $\left(\mathbb{Z}_{n},+_{n}\right)$ adalah contoh dari grup siklik yang dibangun oleh 1 . Sehingga, grup $\left(\mathbb{Z}_{n},+_{n}\right)$ ini juga dapat ditulis $\mathbb{Z}_{n}=\langle 1\rangle^{3}$.

Selanjutnya, jika dimisalkan bahwa $g$ adalah himpunan subgrupsubgrup dari suatu grup $G$ maka relasi subgrup $(\leq)$ terhadap himpunan $g$ merupakan relasi pengurutan parsial. Relasi pengurutan parsial adalah relasi yang memenuhi sifat refleksif, antisimetris, dan transitif. Karena setiap subgrup dari $G$ adalah subgrup pada dirinya sendiri (improper subgrup), maka jelas bahwa relasi subgrup ( $\leq$ ) bersifat refleksif 4 .

Mengingat bahwa subgrup dari suatu grup merupakan himpunan bagiannya, maka jika $G_{1} \leq G_{2}$ yang berarti $G_{1} \subseteq G_{2}$ dan $G_{2} \leq G_{1}$ yang berarti $G_{2} \subseteq G_{1}$ maka berdasarkan definisi kesamaan dua buah himpunan, jelas bahwa $G_{1}=G_{2}$. Ini berarti bahwa relasi subgrup ( $(\leq)$ bersifat antisimetris. Selanjutnya, dengan berdasar pada sifat subgrup, yaitu interseksi dari subgrup-subgrupnya juga merupakan subgrup maka jelas bahwa jika $G_{1} \leq G_{2}$ dan $G_{2} \leq G_{3}$ maka $G_{1} \leq G_{2}$. . Ini berarti bahwa relasi subgrup ( $\leq$ ) bersifat transitif.

Suatu relasi pengurutan parsial dan himpunannya disebut dengan poset. Jika suatu relasi merupakan relasi pengurutan parsial, maka himpunan dan relasinya dapat digambarkan dengan sebuah diagram lattice. Anne Berry and Alain Sigayret dalam penelitiannya yang berjudul representing a concept lattice by a graph membahas dengan lebih rinci mengenai representasi ini.

${ }^{3}$ John B. Fraleigh, A First Course in Abstract Algebra, 7th Edition, 7 edition (Boston: Pearson, 2002), 65.

${ }^{4}$ Kenneth H. Rosen, Discrete Mathematics and Its Applications Seventh Edition, 7th edition (New York, NY: McGraw-Hill Education, 2011), 618.

Al-Khwarizmi - 49 
Sebuah diagram lattice $L$ didefinisikan sebagai poset $(L, \leq)$ yang setiap pasang elemennya memiliki batas atas terkecil dan batas bawah terbesar 5 .

Diagram lattice pada relasi subgrup dan himpunan subgrup-subgrup dari suatu grup dapat dipandang sebagai sebuah graf. Pada representasi ini, himpunan subgrup-subgrup dipandang sebagai himpunan titik-titk dan relasi antar subgrup dipandang sebagai sisi. Sebuah graf $G$ didefinisikan sebagai pasangan himpunan $(V, E)$ dengan $V$ adalah himpunan tidak kosong dari elemen-elemen yang disebut titik (vertex), dan $E$ adalah himpunan (boleh kosong) dari pasangan tidak terurut dua titik $\left(v_{1}, v_{2}\right)$ dimana $v_{1}, v_{1} \in V$, yang disebut sisi (edges). Dalam hal ini, $V$ atau $\mathrm{V}(G)$ disebut himpunan titik dari $G$, dan $E$ atau $E(G)$ disebut himpunan sisi dari G.

Jika titik atau sisi pada graf dilabeli dengan suatu bilangan tertentu sedemikian hingga memenuhi syarat-syarat tertentu, masalah ini selanjutnya dikenal dengan masalah pelabelan. Dalam teori graf, masalah pelabelan masih menjadi topik penelitian yang masih dikaji sampai sekarang. Jika ditinjau dari label titiknya, pelabelan titik dibedakan menjadi pelabelan titik ajaib dan pelabelan titik anti-ajaib. Jika $G=(V, E)$ adalah suatu graf, pelabelan titik ajaib didefinisikan sebagai fungsi bijektif dari $V$ ke $\{1,2, \ldots,|V|\}$ sedemikian hingga setiap bobot sisinya, yaitu jumlah label titik yang dihubungkan oleh sebuah sisi adalah sama. Sedangkan pelabelan titik antiajaib didefinisikan sebagai fungsi bijektif dari $V$ ke $\{1,2, \ldots,|V|\}$ sedemikian hingga bobot sisinya, yaitu jumlah label titik yang dihubungkan oleh sebuah sisi adalah tidak sama. Pada pelabelan titik anti-ajaib, juga didefinisikan pelabelan $(a, d)$-titik anti-ajaib. Pelabelan $(a, d)$-titik anti-ajaib didefinisikan sebagai fungsi bijektif dari $V$ ke $\{1,2, \ldots,|V|\}$ sedemikian hingga bobot sisinya, yaitu jumlah label titik yang dihubungkan oleh sebuah sisi membentuk deret aritmatika dengan suku awal $a$ dan beda $d^{6}$.

${ }^{5}$ Anne Berry and Alain Sigayret, "Representing a Concept Lattice by a Graph," Discrete Applied Mathematics, Discrete Mathematics and Data Mining, 144, no. 1 (November 30, 2004): 72, https://doi.org/10.1016/j.dam.2004.02.016.

6 Joseph Gallian, "A Dynamic Survey of Graph Labeling," Electron J Combin DS6 19 (November 12, 2000): 176. 


\section{Pelabelan Lokal Titik Graf...}

Berbeda dengan konsep pelabelan graf, jika titik-titik pada graf hasil diagram lattice (terutama pada diagram lattice subgrup $\mathbb{Z}_{n}$ ) dilabeli berdasarkan elemen-elemen subgrupnya, maka permasalahan pelabelan yang muncul menjadi sedikit berbeda dengan konsep pelabelan titik di atas. Karena pelabelan pada graf hasil diagram lattice berdasarkan pada elemen subgrupnya maka selanjutnya disebut dengan pelabelan titik lokal. Untuk mengetahui eksistensi pelabelan titik lokal, maka terlebih dahulu perlu dikaji mengenai karakteristik diagram lattice subgrup $\mathbb{Z}_{n}$.

\section{Metode}

Penelitian ini merupakan jenis penelitian eksploratif dengan menggunakan metode deskriptif aksiomatik dan metode Induktif. Metode deduktif aksiomatik merupakan metode penelitian dengan menurunkan aksioma atau teorema - teorema yang sudah ada kedalam permasalahan baru yang akan diselidiki. Dalam penelitian ini, teorema-teorema yang berhubungan dengan grup dan subgrup akan digunakan untuk menentukan karakteristik diagram lattice subgrup $\mathbb{Z}_{n}$. Sedangkan metode induktif merupakan metode penelitian dengan menerapkan kaidah-kaidah khusus untuk mentukan kaidah- kaidah umum. Metode ini akan digunakan ketika menentukan pelabelan titk lokal berdasarkan diagram lattice subgrup $\mathbb{Z}_{n}$ yang dihasilkan.

\section{Karakteristik Diagram Lattice}

Hasil penelitian ini akan dimulai dengan melakukan kajian terhadap karakteristik dari diagram lattice subgrup $\mathbb{Z}_{n}$ kemudian akan dibahas mengenai definisi pelabelan lokal yang dimaksud beserta eksistensinya.

\section{Lema 1}

Jika $\langle a\rangle$ adalah subgrup dari $\mathbb{Z}_{n}, b \in\langle a\rangle$, dan $f p b\left(\frac{n}{a}, \frac{b}{a}\right)=1$ maka $\langle a\rangle=\langle b\rangle$

\section{Bukti:}

Untuk membuktikan $\langle a\rangle=\langle b\rangle$ maka harus dibuktikan bahwa $\langle a\rangle \subseteq\langle b\rangle$ dan $\langle b\rangle \subseteq\langle a\rangle$. Pertama-tama, ambil sebarang $x \in\langle b\rangle$. $x$ dapat ditulis dalam bentuk $x=b^{k}$, untuk suatu $k \in \mathbb{Z}$. Karena $b \in\langle a\rangle$ maka $b$ juga dapat ditulis dalam Al-Khwarizmi - 51 
bentuk $b=a^{l}$, untuk suatu $l \in \mathbb{Z}$. Sehingga diperoleh, $x=\left(a^{l}\right)^{k}=a^{s}$, untuk suatu $s \in \mathbb{Z}$. Ini berarti bahwa $x \in\langle a\rangle$. Akibatnya, dapat disimpulkan bahwa $\langle b\rangle \subseteq\langle a\rangle$.

Sebaliknya, karena $f p b\left(\frac{n}{a}, \frac{b}{a}\right)=1$ maka akan ada bilangan bulat $i$ dan $j$ sedemikian hingga $\frac{n}{a} i+\frac{b}{a} j=1$. Dengan demikian, diperoleh

$$
a=n i+b j \equiv b j(\bmod n)=b+{ }_{n} b+{ }_{n} \ldots+_{n} b=b^{j} \in \mathbb{Z}_{n}
$$

Sehingga, jika diambil sebarang $y \in\langle a\rangle$, maka $y$ dapat ditulis dalam bentuk

$$
y=a^{t}=\left(b^{j}\right)^{t}=b^{u}
$$

untuk suatu $t, u \in \mathbb{Z}$. Ini berarti bahwa $y \in\langle b\rangle$. Akibatnya, dapat disimpulkan bahwa $\langle a\rangle \subseteq\langle b\rangle$. Karena $\langle b\rangle \subseteq\langle a\rangle$ dan $\langle a\rangle \subseteq\langle b\rangle$ maka jelas bahwa $\langle a\rangle=\langle b\rangle$. (terbukti)

\section{Contoh 1}

Berdasarkan Lemma 1, dapat dicari subgrup-subgrup dari grup $\left(\mathbb{Z}_{12},{ }_{12}\right)$, sebagai berikut.
1. $\langle 1\rangle=\{0,1,2,3,4,5,6,7,8,9,10,11\}=\langle 5\rangle=\langle 7\rangle=\langle 11\rangle$
2. $\langle 2\rangle=\{0,2,4,6,8,10\}=\langle 10\rangle$
3. $\langle 3\rangle=\{0,3,6,9\}=\langle 9\rangle$
4. $\langle 4\rangle=\{0,4,8\}=\langle 8\rangle$
5. $\langle 6\rangle=\{0,6\}$
6. $\langle 0\rangle=\{0\}$

Jika digambar diagram latticenya, diperoleh

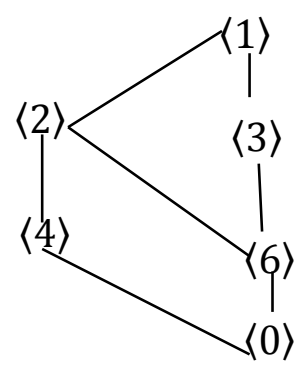

Gambar 1. Diagram Lattice grup $\left(\mathbb{Z}_{12},+_{12}\right)$ 


\section{Pelabelan Lokal Titik Graf...}

Berdasarkan Lemma 1, maka diperoleh akibat sebagai berikut.

Akibat 1

Jika $p_{1}, p_{2}, \ldots, p_{k}$ adalah bilangan prima dan $n=p_{1} . p_{2} \ldots p_{k}$ maka banyaknya subgrup dari $\mathbb{Z}_{n}$ adalah $\left(p_{1}+1\right)\left(p_{1}+2\right) \ldots\left(p_{k}+1\right)$

\section{Pelabelan Lokal dan Eksistensinya}

Untuk pembahasan mengenai pelabelan titik graf dari diagram lattice berdasarkan elemen subgrupnya yang selanjutnya disebut sebagai pelabelan lokal titik, berikut terlebih dahulu akan didefinisikan beberapa istilah pelabelan yang dimaksud. Sebagai catatan, istilah pelabelan pada pembahasan selanjutnya ditujukan untuk pelabelan graf hasil diagram lattice subgrup $\mathbb{Z}_{n}$. Label titik diambil dari elemen-elemen subgrup representasi titik yang direpresentasikan.

\section{Definisi 1}

Pelabelan lokal titik ajaib adalah pemasangan satu elemen subgrup pada titik representasinya sedemikian hingga setiap bobot sisinya, yaitu jumlah label titik yang dihubungkan oleh sebuah sisi adalah sama.

\section{Definisi 2}

Pelabelan lokal titik anti-ajaib adalah pemasangan satu elemen subgrup pada titik representasinya sedemikian hingga bobot sisinya, yaitu jumlah label titik yang dihubungkan oleh sebuah sisi adalah tidak sama.

\section{Definisi 3}

Pelabelan lokal $(a, d)$-titik anti-ajaib adalah pemasangan satu elemen subgrup pada titik representasinya sedemikian hingga bobot sisinya, yaitu jumlah label titik yang dihubungkan oleh sebuah sisi membentuk deret aritmetika dengan suku awal $a$ dan beda $d$.

Berdasarkan definisi tersebut, maka dimungkinkan ada beberapa titik dengan label yang sama. Karena 0 adalah elemen dari sebarang grup, maka 
jika setiap titik diberi label 0 , maka jelas bobot setiap sisinya adalah sama. Ini berarti bahwa pelabelan yang dimaksud adalah pelabelan lokal titik ajaib. Begitu juga untuk graf hasil diagram lattice $\mathbb{Z}_{p^{k}}$ untuk suatu bilangan prima $p$ dan bilangan positip $k$. Berdasarkan Akibat 1 , banyaknya subgrup $\mathbb{Z}_{p^{k}}$ adalah $k+1$. Graf yang dihasilkan berdasarkan diagram latticenya berbentuk graf lintasan dengan panjang k seperti Gambar 2 berikut.

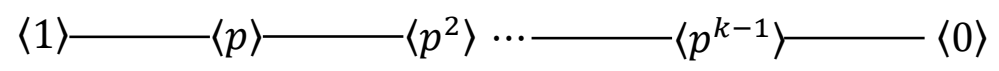

Gambar 2. Diagram Lattice grup $\left(\mathbb{Z}_{p^{k}},{ }_{p^{k}}\right)$

Jika pada titik representasi subgrup $\langle 0\rangle$ dilabeli 0 , titik representasi subgrup $\left\langle p^{k-1}\right\rangle$ dilabeli $p^{k-1}$, titik representasi subgrup $\left\langle p^{k-2}\right\rangle$ dilabeli 0 , titik representasi subgrup $\left\langle p^{k-3}\right\rangle$ dilabeli $p^{k-1}$, dan seterusnya berselang seling hingga label titik representasi $\langle 1\rangle$, maka akan diperoleh bobot sisi yang sama yaitu $p^{k-1}$. Namun pelabelan yang demikian tidak menarik untuk dibahas. Hal yang menariknya, apakah yang terjadi jika label 0 hanya boleh dipakai oleh subgrup trivial $\langle 0\rangle$ ? Adakah pelabelan lokal titik ajaibnya? Adakah pelabelan lokal titik anti-ajaibnya?

Berikut, beberapa lema hasil pelabelan lokal titik graf hasil diagram lattice $\mathbb{Z}_{n}$ untuk $n$ tertentu.

\section{Lema 2}

Jika $p \neq q$ keduanya adalah bilangan prima maka terdapat pelabelan lokal titik anti-ajaib pada graf hasil diagram lattice $\mathbb{Z}_{p q}$

Bukti:

Berdasarkan Akibat 1, banyaknya subgrup $\mathbb{Z}_{p q}$ adalah 4, yaitu

1. $\langle 1\rangle=\{0,1,2, \ldots, p q-1\}$

2. $\langle p\rangle=\{0, p, 2 p, 3 p, \ldots,(q-1) p\}$

3. $\langle q\rangle=\{0, q, 2 q, 3 q, \ldots,(p-1) q\}$

4. $\langle 0\rangle=\{0\}$ 
Jika graf hasil diagram lattice $\mathbb{Z}_{p q}$ dilabeli seperti Gambar 3 berikut:

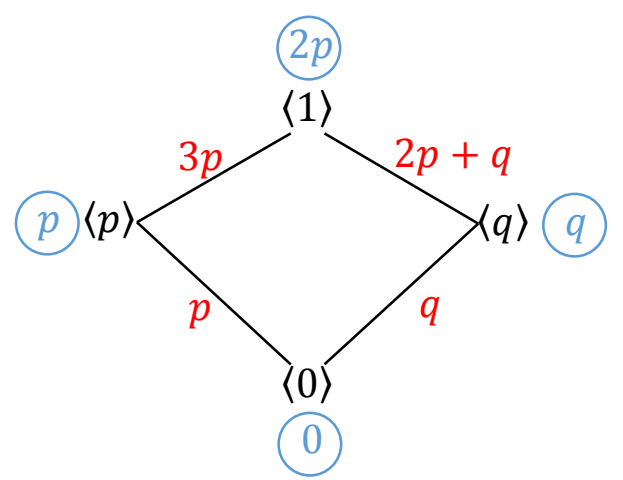

Gambar 3. Pelabelan Lokal Titik Anti-ajaib Diagram Lattice grup $\left(\mathbb{Z}_{p q},{ }_{p q}\right)$

Karena $p, q, 3 p$, dan $2 p+q$ keempatnya tidak sama, maka jelas bahwa dengan aturan pelabelan yang demikian, terbukti bahwa pada graf hasil diagram lattice $\mathbb{Z}_{p q}$ terdapat pelabelan lokal titik anti-ajaib.

\section{Akibat 2}

Jika $p$ dan $q$ adalah bilangan prima dan $p=q+2$ maka terdapat pelabelan lokal $(a, 1)$-titik anti-ajaib pada graf hasil diagram lattice $\mathbb{Z}_{p q}$

\section{Bukti:}

Jika graf hasil diagram lattice $\mathbb{Z}_{p q}$ dilabeli seperti Gambar 4 berikut,

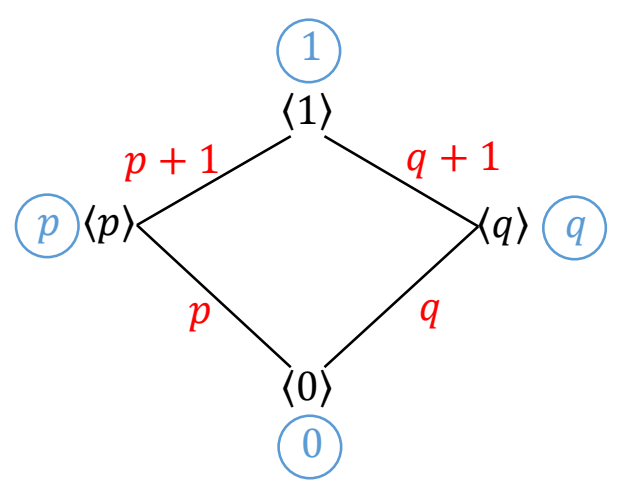

Gambar 4. Pelabelan Lokal $(a, 1)$-Titik Anti-ajaib Diagram Lattice grup

$$
\left(\mathbb{Z}_{p q},+_{p q}\right)
$$


Perhatikan bahwa:

$$
q, q+1, p=q+2, p+1=q+3
$$

membentuk deret aritmetika dengan suku awal $q$ dan beda 1 . Ini menunjukkan bahwa terdapat pelabelan lokal $(a, 1)$-titik anti-ajaib pada graf hasil diagram lattice $\mathbb{Z}_{p q}$.

\section{Simpulan}

\section{Penutup}

Berdasarkan uraian pada hasil dan pembahasan di atas, dapat disimpulkan bahwa karakteristik diagram lattice dari subgrup $\mathbb{Z}_{n}$ ada hubungannya dengan faktorisasi bilangan prima dari $n$, yaitu banyaknya subgrupnya sama dengan banyaknya faktor positif dari $n$. Konsep pelabelan lokal titik dalam uraian di atas tidaklah sama dengan pelabelan graf pada umumnya, sehingga rumus umum pelabelan titik yang ditemukan seperti contoh graf lintasan tidak dapat digunakan untuk pelabelan di sini. Untuk $n=p q$ dengan $p \neq q$ keduanya adalah bilangan prima, telah ditunjukkan mengenai keberadaan pelabelan titik anti-ajaibnya. Khususnya, untuk $p=q+2$, juga terdapat pelabelan lokal $(a, 1)$-titik anti-ajaib.

\section{Saran}

Saran untuk penelitian selanjutnya adalah perlunya dicari keberadaan pelabelan titik ajaib, anti ajaib, atau $(a, d)$-titik anti-ajaib untuk $n$ lainnya.

\section{Daftar Pustaka}

Berry, Anne, and Alain Sigayret. "Representing a Concept Lattice by a Graph." Discrete Applied Mathematics, Discrete Mathematics and Data Mining, 144, no. 1 (November 30, 2004): 27-42. https://doi.org/10.1016/j.dam.2004.02.016.

Fraleigh, John B. A First Course in Abstract Algebra, 7th Edition. 7 edition. Boston: Pearson, 2002.

Gallian, Joseph. "A Dynamic Survey of Graph Labeling." Electron J Combin DS6 19 (November 12, 2000).

Herstein, I. N. Abstract Algebra 3th (Third) Edition. Example Product Manufacturer, 1996.

Roberts, Charles. Introduction to Mathematical Proofs: A Transition. 1 edition. Boca Raton: Chapman and Hall/CRC, 2009.

Rosen, Kenneth H. Discrete Mathematics and Its Applications Seventh Edition. 7th edition. New York, NY: McGraw-Hill Education, 2011. 